\title{
0 creditamento do IPI sob a perspectiva jurisprudencial
}

The IPI crediting from the jurisprudential perspective

\author{
Eliane Demétrio ${ }^{1}$ \\ Ingredy G. T. de Jesus Borges ${ }^{2}$ \\ Lígia Maria Deganello ${ }^{3}$
}

\section{Resumo}

0 presente artigo visa analisar o creditamento do IPI na aquisição de matériasprimas e insumos sob o regime da isenção, alíquota zero ou não-tributação, como um meio de concretizar o princípio da não-cumulatividade, esculpido no art. 153, § $3^{\circ}$, II, da Constituição Federal, e de atingir a finalidade do instituo da exoneração tributária. Para tanto, analisa o entendimento jurisprudencial do Supremo Tribunal Federal de acordo com os princípios constitucionais aplicáveis ao IPI, considerandose os precedentes de 1998 e 2007.

Palavras Chave: Creditamento; IPI; Não-cumulatividade; Isenção; Não-tributação; Alíquota-zero.

\section{Abstract}

This article aims to analyze the crediting of the IPI in the acquisition of raw materials and inputs under the system of exemptions, zero rate or non-taxation as a way to realize the principle of non-cumulative, carved in the art. $153, \S 3$, II, of the Federal Constitution, and to achieve the purpose of the institute's tax exemption. It analyzes the jurisprudential understanding of the Supreme Court in accordance with the constitutional principles applicable to the IPI, by the consideration of the precedents of 1998 and 2007.

Keywords: Crediting; IPI; Non-cumulative; Exemption; Non-taxation; zero-tax rate.

\section{Introdução}

O princípio constitucional da não-cumulatividade ganha especial destaque no tocante ao Imposto sobre Produtos Industrializados - IPI, por trazer à baila discussões como o direito de crédito tributário em operações cuja entrada de insumos e matérias-primas

\footnotetext{
${ }^{1}$ Graduada do curso de Direito da Universidade Estadual de Londrina.

${ }^{2}$ Graduada do curso de Direito da Universidade Estadual de Londrina.

${ }^{3}$ Graduada do curso de Direito da Universidade Estadual de Londrina.
} 
tenham sido beneficiadas com alguma forma de exoneração tributária (isenção, alíquota zero ou não-tributação).

A questão, contudo, não se mostra simples. Existem robustos argumentos tanto no sentido de defender a ofensa ao citado princípio, ante a vedação do creditamento do IPI, como no sentido de defender a constitucionalidade de interpretação diversa.

Ambos os posicionamentos serão objeto de estudo do presente artigo, cujo enfoque principal se fará sob os precedentes do Supremo Tribunal Federal firmados nos anos de 1998 e 2007. Antes, contudo, insta ressaltar, em uma sucinta análise, o conteúdo e extensão do princípio da não-cumulatividade, previsto no artigo 153, § 30, inciso II, da Constituição Federal, para, na seqüência, dar início ao estudo das decisões paradigmas exaradas pela Suprema Corte brasileira.

\section{Sistema de creditamento do IPI: princípio da não-cumulatividade}

O sistema de creditamento do Imposto sobre Produtos Industrializados (IPI) constitui o cerne do princípio constitucional da não-cumulatividade, que possibilita ao contribuinte, em cada operação, uma dedução correspondente aos montantes cobrados nas operações anteriores, consoante determina o art. 153, § 30, II, da Constituição Federal (CF).

Conforme Eduardo Domingos Bottallo (2002, p. 210) o direito à compensação:

Deve ser analisado e interpretado sob a generosa ótica da isonomia, pois atenta contra este elevadíssimo cânone aceitar-se a idéia de que a Fazenda Pública sendo, ao mesmo tempo, credora e devedora de determinado sujeito passivo, possa dele exigir o pagamento de seus créditos, sem que se disponha, também, a satisfazer seus débitos.

0 creditamento do IPI, portanto, consiste na compensação dos valores creditados com os valores debitados em determinado período de tempo. Como bem assevera José Eduardo Soares de M elo (2006, p.571):

0 crédito nasce de operações anteriores relativas à aquisição de bens necessários e utilizáveis pelo industrial, direta ou indiretamente, na fabricação de produtos, compreendendo-se os insumos (matérias-primas, materiais auxiliares, de embalagem e produtos intermediários) e bens do ativo (imobilizado), uso e consumo do estabelecimento. 
Além da previsão constitucional, o Código Tributário Nacional (CTN) traz em seu bojo semelhante disposição ao estabelecer que "o saldo verificado em determinado período, em favor do contribuinte, transfere-se para o período ou períodos seguintes" (art. 49, parágrafo único).

Na mesma dicção, tem-se 0 art. 163 do Regulamento do Imposto sobre os Produtos Industrializados (RIPI, Decreto ${ }^{\circ}$ 4.544/02): "a não - cumulatividade do imposto é efetivada pelo sistema de crédito, atribuído ao contribuinte, do imposto relativo a produtos entrados no seu estabelecimento, para ser abatido do que for devido pelos produtos dele saídos, num mesmo período".

Assim, os valores tributários (créditos e débitos), constante das notas fiscais, devem ser devidamente registrados em livros fiscais relativos às entradas e saídas, controle da produção e do estoque, inventário e apuração do IPI, para que ao final seja possível a verificação do montante a ser creditado.

Para melhor elucidar esse ponto, Hugo de Brito Machado (2003, p. 498) cita o seguinte exemplo:

Em uma empresa industrial, por exemplo, isto significa dizer o seguinte: a) faz-se 0 registro, como crédito, do valor do IPI relativo às entradas de matérias - primas, produtos intermediários, materiais de embalagens e outros insumos, que tenham sofrido a incidência do imposto ao saírem do estabelecimento de onde vieram; b) faz-se o registro, como débito, do valor do IPI calculado sobre os produtos que saírem. No fim do mês é feita a apuração. Se o débito é maior, o saldo do devedor corresponde ao valor a ser recolhido. Se o crédito é maior, o saldo credor é transferido para o mês seguinte.

Em relação ao creditamento, questão polêmica desponta acerca da possibilidade da fruição de créditos de IPI quando se adquire produtos (insumos, matérias-primas, etc.) que serão utilizados na industrialização sob a forma isenta, com alíquota zero ou não-tributado, tendo em vista a recentíssima alteração do entendimento do Supremo Tribunal Federal (STF). 


\section{Crédito do IPI relativo à aquisição de produtos isentos, com alíquota zero ou não-}

\section{tributados: entendimento jurisprudencial até 2007}

A Constituição Federal, ao contrário do expressamente previsto para o ICM, no art. 155, §2ำ II, não impôs qualquer restrição à fruição do crédito do IPI, vale dizer, não instituiu vedação à utilização do crédito do referido imposto na aquisição e/ou saída de produtos com exoneração tributária (não-tributado, isento ou com alíquota zero). Desta maneira, pode-se afirmar que o "princípio da não-cumulatividade não sofre nenhuma limitação ou exceção na Constituição" (DERZI apud BOTTALLO, 2002, p. 52).

A doutrina e a jurisprudência entendiam, até dezembro de 2007, ser pleno o direito ao crédito do IPI, mesmo nos casos de aquisições isentas, imunes ou sujeitas à alíquota zero. 0 marco inicial que firmou tal entendimento foi o julgamento do Recurso Extraordinário $\mathrm{n}^{\circ}$ 212.484-2, originário do Rio Grande do Sul e publicado no Diário de Justiça da União em 27.11.1998, que tem sua ementa vertida nos seguintes termos:

Ementa Constitucional. Tributário. IPI. Isenção. Incidente sobre Insumos. Direito de Crédito. Princípio da Não-cumulatividade. Ofensa não caracterizada. Não ocorre ofensa à CF (ART. 153, §3으, II) quando o contribuinte do IPI credita-se do valor do tributo incidente sobre insumos adquiridos sob o regime da isenção. Recurso não conhecido (BRASIL. Supremo Tribunal Federal. RE 212.484-2/RS. Relator M inistro Nelson Jobim, Pleno. DJU 27/11/98) (grifos nossos).

Assentou-se neste acórdão importantes pontos que ressaltam a necessidade do creditamento do IPI em operações com exonerações tributárias, que se encontram muito bem destacadas por José Eduardo Soares de Melo (2006, p.573):

a) a negativa do direito ao crédito do IPI, em operações isentas, tornaria o imposto cumulativo, inviabilizando essas desonerações tributárias durante 0 processo produtivo;

b) a restrição constitucional ao crédito operou-se exclusivamente para o ICMS;

c) o crédito é imprescindível para não transformar a isenção em simples diferimento, projetando no tempo o recolhimento do tributo;

d) a negativa do crédito corresponderia à anulação do benefício da isenção, não se podendo acolher a diretriz que importe em reconhecer a possibilidade de 0 Estado dar com uma das mãos e retirar com a outra (grifos nossos).

De acordo com o entendimento esposado no RE 212/484-2/RS, a possibilidade do creditamento surge pela interpretação não literal da expressão "cobrado" estatuída no art. 
$153 \S 3^{\circ}$, II da CF. Em outras palavras, a expressão "cobrado" deve ser compreendida no sentido de "incidência" e não de efetiva cobrança do imposto. Corrobora com esse entendimento do jurista Hugo de Brito Machado:

Seja como for, inadmissível é a interpretação literal dos preceitos da Constituição Federal, e do Código Tributário Nacional, quanto às palavras cobrado, contida no art. 153, inciso IV, e $\S 3^{\circ}$, inciso II, e pago, contida no art. 49 do Código Tributário Nacional. Qualquer pessoa que tenha alguma vivência da sistemática da não-cumulatividade, sabe perfeitamente que jamais o fisco exigiu de qualquer contribuinte a prova da cobrança, ou do pagamento, como condição para o uso do crédito correspondente. Em face da isenção, este imposto, relativo à operação anterior, ou não será devido, ou será devido, mas dispensado em virtude de norma isentiva, mas não pode ser desconsiderado, porque isso implicaria abolir 0 instituto da isenção, que restaria substituído inexoravelmente pelo instituto do diferimento de incidência (2006, p. 501).

No mesmo sentido, explica Eduardo Domingos Bottallo (2002, p. 47):

(...) o direito de crédito em consideração não está preso ao efetivo pagamento do imposto, nas operações anteriores. (...) 0 abatimento é devido até mesmo nos casos em que as operações anteriores sejam isentas ou, de qualquer outro modo, desoneradas da incidência do tributo.

Há que se salientar, que a alíquota a ser utilizada para a tomada dos créditos no caso de insumos e matérias-primas não-tributadas, isentas ou com alíquota zero, deve ser a mesma, ou seja, os "créditos e débitos deverão adotar o mesmo parâmetro para as respectivas quantificações" (BOTTALLO, 2006, p. 54). 0 uso de alíquota superior àquela que dimensiona 0 débito geraria enriquecimento ilícito por parte do contribuinte e a alíquota inferior, por conseqüência, o aviltamento indevido do direito que lhe cabe.

Deste modo, pelo posicionamento do referido acórdão verificava-se que a aquisição de insumos isentos de IPI gerava o direito ao creditamento do valor do IPI que teria sido pago caso não houvesse a isenção; ou seja, permanecia na íntegra o direito ao crédito do referido imposto em operações isentas, não-tributadas ou com aplicação de alíquota zero, na tentativa de se preservar o princípio da não-cumulatividade do IPI, que, como já explicitado, não possui qualquer restrição constitucional à respeito. 


\title{
Atual entendimento jurisprudencial: impossibilidade de creditamento
}

Conforme visto, no aludido RE 212.484-2/RS publicado no Diário de Justiça da União em 27.11.1998, o Supremo Tribunal Federal decidiu que não configuraria ofensa à Lei M aior o contribuinte do IPI creditar-se do valor do tributo incidente sobre insumos isentos, não tributados ou sujeitos à alíquota zero.

No entanto, no ano de 2007, com o julgamento do RE 370.682/RS, o Plenário da Suprema Corte, ao tratar da questão do creditamento do IPI nos casos de aquisições de produtos com exonerações tributárias, alterou o seu posicionamento anteriormente firmado.

No precedente judicial supracitado, o Supremo Tribunal Federal decidiu que não implica em violação do princípio constitucional da não-cumulatividade a impossibilidade de creditamento do IPI para o contribuinte adquirente de insumos desonerados, senão vejamos:

\begin{abstract}
Recurso extraordinário. Tributário. 2. IPI. Crédito Presumido. Insumos sujeitos à alíquota zero ou não tributados. Inexistência. 3. Os princípios da nãocumulatividade e da seletividade não ensejam direito de crédito presumido de IPI para o contribuinte adquirente de insumos não tributados ou sujeitos à alíquota zero. 4. Recurso extraordinário provido (BRASIL. Supremo Tribunal Federal. RE 370.682/SC. Relator Ministro Ilmar Galvão. Julgamento 25.06.2007. Órgão Julgador: Tribunal Pleno. DJU: 19.12.2007). (grifos nossos)
\end{abstract}

Seguindo essa mesma linha, o recente acórdão do RE 353.657/PR entendeu que em razão do princípio da não-cumulatividade "não se pode cogitar de direito a crédito quando 0 insumo entra na indústria considerada a alíquota zero".

0 atual posicionamento do Supremo - que afastou o entendimento firmado no precedente RE 212.484/RS - consolidou-se no sentido de que o princípio da nãocumulatividade não oferece ao contribuinte que adquire insumos não-tributados ou sujeitos à alíquota zero o direito ao crédito do valor concernente ao IPI.

Assim, de acordo com esse novo entendimento fixado pelo STF a interpretação da expressão "cobrado", constante no art. $153, \S 3^{\circ}, \mathrm{Il}$, da CF, deve equivaler à expressão "pago" e não "incidido", como se entendia anteriormente.

Partindo dessa perspectiva, a Suprema Corte firmou entendimento de que apenas os valores efetivamente recolhidos na operação anterior é que geram créditos do IPI, de 
modo que só haverá direito ao creditamento quando houver a cobrança do tributo na aquisição de insumos ou matérias-primas (ALVES JÚNIOR, 2008).

Diante dessa interpretação que foi dada ao contido no art. 153 , $\S 3^{\circ}$, II, da CF, verificou-se que a impossibilidade do creditamento tributário no IPI decorre da ausência da cobrança do imposto na operação de entrada referente à aquisição de insumos nãotributados ou sujeitos à alíquota zero. Nas palavras do Ministro Marco Aurélio "não tendo sido cobrado nada, absolutamente nada, nada há de ser compensado, mesmo porque inexiste a alíquota que, incidido, por exemplo, sobre o valor do insumo revelaria a quantia a ser considerada" (RE 353.657/PR).

Nesse tocante, emerge a questão de saber se 0 atual posicionamento do Supremo Tribunal Federal abrange ou não as hipóteses de aquisição de produtos isentos, haja vista que o precedente RE 370.682/SC se referiu apenas à impossibilidade de creditamento para o caso de aquisição de produtos não-tributados ou tributados com alíquota zero. A controvérsia envolvida nesse caso bifurca-se em dois entendimentos diametralmente opostos.

Pelo entendimento firmado no RE 391.822/RS ocorre na isenção o direito ao crédito de IPI, de modo que a decisão do STF, que trata da impossibilidade de creditamento do IPI, se adstringiria tão-somente às aquisições não-tributadas ou sujeitas à alíquota zero. Veja-se:

\begin{abstract}
AGRAVO REGIMENTAL EM RECURSO EXTRAORDINÁRIO. IPI. INSUMOS E MATÉRIAS-PRIMAS NÃO TRIBUTADOS OU SUJEITOS À ALÍQUOTA ZERO. CREDITAMENTO. IM POSSIBILDADE. AGRAVO IMPROVIDO. I- Impossibilidade de creditamento do IPI referente a insumos e matérias-primas não tributados ou sujeitos à alíquota zero. Precedentes do Pleno (RE 353.657/PR, Rel. Min. Marco Aurélio, e RE 370.682/SC, Rel. para o acórdão o Min. Gilmar Mendes). IIInexistência de violação ao principio da não-cumulatividade. III- agravo regimental improvido (BRASIL. Supremo Tribunal Federal. RE- AgR 391.822/RS. Relator M inistro Ricardo Lewandowski. Julgamento: 02.09.2008. Órgão Julgador: 1 ạ Turma. DJU: 19.09.2008). (grifos nossos)
\end{abstract}

Esse primeiro posicionamento se justifica pelo fato de que "a decisão ora atacada restringiu-se ao exame das hipóteses de não-tributação e alíquota zero, conforme o pedido do recurso ordinário, não abrangendo os casos de aquisição de insumos e matérias-primas isentas" (LEWANDOWSKI, RE 391.822/RS).

Não obstante, o segundo entendimento consubstanciado no RE 372.005/PR, estendeu aos insumos isentos o precedente que trata dos insumos não-tributados ou 
tributados com alíquota zero. Logo, a decisão que impossibilita o creditamento dos produtos não-tributados ou sujeitos à alíquota zero abrangeria, de igual forma, os isentos. Senão vejamos:

\begin{abstract}
AGRAVO REGIMENTAL NO RECURSO EXTRAORDINÁRIO. IPI. INSUMOS ISENTOS, NÃO TRIBUTADOS OU SUJEITOS À AĹQUOTA ZERO. PRINCÍPIO DA NÃOCUMULATIVIDADE. CRÉDITO PRESUMIDO. INEXISTENCIA. MODULAÇÃO TEM PORAL DOS EFEITOS DA DECISÃO. INAPLICABILDADE. 1. A expressão utilizada pelo constituinte originário - montante "cobrado" na operação anterior- afasta a possibilidade de admitir-se 0 crédito de IPI nas operações de que se trata, visto que nada teria sido "cobrado" na operação de entrada de insumos isentos, não tributados ou sujeitos à alíquota zero. Precedentes. 2. 0 Supremo entendeu não ser aplicável ao caso a limitação de efeitos da declaração de inconstitucionalidade. Precedentes. Agravo regimental a que se nega provimento (BRASIL. Supremo Tribunal Federal. RE - AgR 372.005/PR. Relator M inistro Eros Grau. Julgamento: 29.04.2008. Órgão Julgador: 2a Turma. DJU: 16.05.2008). (grifos nossos)
\end{abstract}

Acerca dessa possibilidade, o M inistro Eros Grau explica o seguinte:

No que respeita ao direito ao crédito presumido relativo à entrada de matériasprimas e demais insumos isentos, não obstante tratar-se de instituto diverso da não-tributação (produto não compreendido na esfera material da incidência do tributo) e da incidência da alíquota zero (redução da alíquota ao fator zero), a consideração do princípio da não-cumulatividade conduz à aplicação, ao caso, da mesma orientação fixada nos precedentes. (RE 372.005/PR).

Destarte, é importante ressaltar que como essa questão ainda não se encontra pacificada, tramita no RE 370.682/RS embargos de declaração - em pauta para julgamento desde 18.04.08 - para esclarecer se a decisão proferida pelo Supremo Tribunal Federal, no caso da inviabilidade do creditamento do IPI, atingiria toda e qualquer forma de exoneração tributária.

Nota-se, ao final, que o atual posicionamento da Suprema Corte quanto à impossibilidade do creditamento para o caso de aquisições isentas, não-tributadas ou sujeitas à alíquota zero não se mostra como o mais adequado, já que a inviabilidade do direito ao crédito do IPI faz com que o princípio da não-cumulatividade e o instituto da isenção não sejam efetivamente alcançados, conforme será analisado. 


\section{Da importância do creditamento do IPI nas operações de entrada, envolvendo aquisição}

\section{de produtos isentos, com alíquota zero ou não-tributados}

Em que pese 0 respeitável posicionamento do Supremo Tribunal Federal, em relação à impossibilidade de creditamento do IPI nas operações em que há aquisição de produtos com exoneração tributária, a vedação desse direito ao contribuinte fere do modo inequívoco o princípio constitucional da não-cumulatividade e, por conseguinte, retira do instituto da isenção a finalidade a ela conferida pelo Texto Magno.

Ora, o princípio da não-cumulatividade, segundo ensina Hugo de Britto Machado (2007, p. 355), "existe para impedir que o ônus do imposto se vá acumulando em cada operação", pois, do contrário, estar-se-ia impondo ao contribuinte uma carga tributária muito além daquela prevista legalmente.

Se $o$ intuito desse princípio é, justamente, a não permissão do acúmulo de duas ou mais incidências do IPI sobre um mesmo produto industrializado, de modo a possibilitar ao contribuinte a fruição do respectivo crédito, qualquer óbice nesse sentido colide frontalmente com a disposição constitucional do art. $153, \S 3^{\circ}$, II, da CF - ainda que 0 insumo utilizado na produção do bem tenha sido beneficiado com alguma forma de exoneração tributária.

E mais. Ao negar o direito de escrituração do crédito de IPI decorrente de aquisições de produtos desonerados, especialmente na hipótese da isenção, o Fisco suprimirá desta a finalidade que the é inerente: de proporcionar incentivo fiscal ao contribuinte. Nas palavras de Hugo de Britto Machado (2003, p. 501):

Pode parecer que não tendo sido cobrado o IPI na operação, em face da isenção, não existiria o direito ao crédito. Tal entendimento, porém, levaria à supressão pura e simples das isenções, que restariam convertidas em meros diferimentos de incidência. Em casos como o que se cuida, o incentivo consubstanciado na isenção concedida às indústrias sediadas em Manaus restaria inteiramente anulado. 0 que a Fazenda deixasse de arrecadar, a título de IPI, do produtor da matéria-prima, no Amazonas, seria por ela tranqüilamente recuperado, com a cobrança do valor respectivo às empresas que utilizam aquela matéria-prima. (BRASIL. Tribunal Regional Federal da 4a Região. AMS 1999.70.09.003939-5/PR. Relator Desembargador Federal Wellington M. de Almeida. Órgão Julgador: $1^{a}$ Turma. DJU: 05.02.2003). (grifos nossos) 
Explica o citado autor que em tais situações seria mais vantajosa a aquisição de insumos e matérias-primas fora da Zona Franca de Manaus, porquanto possibilitaria ao adquirente o creditamento do IPI nas operações subseqüentes (2003, p. 501-502.). Isto ocorrer pelo fato de ser o IPI um imposto indireto, cujo ônus da obrigação tributária acaba por recair sob o contribuinte de fato, e não sob o contribuinte de direito.

Havendo, pois, o repasse dessa carga tributária ao contribuinte de fato (outros estabelecimentos industriais, por exemplo), para que não ocorra o acúmulo de tributação do IPI sobre o produto final é imprescindível que a incidência fiscal alcance somente 0 valor agregado ao produto, isto é, que se credite o valor de IPI já incidido na operação anterior para que as operações subseqüentes sejam tributadas apenas naquilo que efetivamente incorporar ao produto.

Neste sentido, o julgado do Tribunal Regional Federal da 4ạ Região:

TRIBUTÁRIO. IMPOSTO SOBRE PRODUTOS INDUSTRIALIZADOS - IPI. MATÉRIASPRIMAS E INSUMOS ISENTOS. NÃO-TRIBUTADOS OU TRIBUTADOS À AÚQUOTA ZERO. PRODUTO FINAL TRIBUTADO. POSSIBILIDADE DE CREDITAMENTO. PRAZO DECADENCIAL. COM PENSAÇÃO. CORREÇÃO M ONETÁRIA.

1. O princípio da não-cumulatividade, insculpido no artigo 153 , § 3ㄴ, II, da Constituição Federal, deve ser observado em todas as etapas do processo produtivo, inclusive se houver o emprego de matérias-primas ou insumos isentos, não-tributados ou tributados à alíquota zero no processo de industrialização do produto. Se for eliminada a possibilidade de aproveitamento do crédito de IPI referente a insumos adquiridos sem a incidência dessa exação, estar-se-á anulando o tratamento privilegiado, pois a alíquota do tributo recairá sobre a totalidade do valor do produto industrializado e não somente sobre o valor agregado. (...). (grifos nossos)

Para uma melhor compreensão da temática ora abordada, necessária faz-se a transcrição de um excerto do voto vencido do Ministro Ricardo Lewandowski, proferido no Recurso Extraordinário 353.657-5/PR:

Com todas as vênias aos que não concordam com a tese, constitui um equívoco afirmar-se que os contribuintes não incorrem em quaisquer ônus nas transações isentas. Trata-se, com efeito, de uma meia-verdade, visto que eles são onerados de forma indireta, pois, dependendo da alíquota e da forma de compensação do tributo, o custo final do produto será menor ou maior, influindo positiva ou negativamente em sua colocação no mercado.

Isso foi corretamente demonstrado pelo Ministro Nelson Jobim em seu voto proferido no RE 350.446, do qual extraio o trecho abaixo:

'A isenção, a alíquota-zero e a não-tributação objetivam levar, ao mercado, o produto final com menor oneração tributária. 


\begin{abstract}
Beneficiam - é certo - os produtores dos insumos intercorrentes em cujo elo da cadeia produtiva ocorram.

Eles não recolhem tributo.

Mas, não beneficiam só a eles.

Beneficiam, sim e principalmente, o produto, quando, ao final, chega ao mercado com menor carga tributária.

0 objetivo último é dar maior competitividade ao produto, Negar o creditamento é negar que os efeitos da isenção, alíquota-zero e nãotributação alcancem o custo final do produto'.

Em suma, impedir o creditamento nas operações isentas significa onerar toda a cadeia produtiva, e essa, certamente, não foi a intenção do legislador, devendo em conseqüência ser afastada toda interpretação que anule a finalidade da isenção. (BRASIL. Supremo Tribunal Federal. RE - 353.657-5/PR. Relator Ministro Marco Aurélio. Julgamento: 25.06.2007. Órgão Julgador: Tribunal Pleno. DJU: 07.03.2008). (grifos nossos)
\end{abstract}

Não obstante o prevalecimento de tese contrária no Supremo Tribunal Federal (RE 370.682/RS), entendimento diverso há que ser defendido, mormente considerando-se uma interpretação sistêmica do ordenamento jurídico pátrio.

Observa-se, portanto, que a possibilidade de creditamento do IPI em operações beneficiadas pela isenção, alíquota zero e não-tributação constitui insofismável direito do contribuinte, uma vez que visa assegurar o respeito ao princípio constitucional da nãocumulatividade e garantir que as exonerações tributárias atinjam seu escopo.

\title{
Conclusão
}

Em que pese o precedente judicial do Supremo Tribunal Federal ter fixado novo posicionamento quanto ao creditamento do IPI em operações cuja entrada de produtos tenha sido beneficiada pela isenção, alíquota zero ou não-tributação, o entendimento que se afigura mais adequado, com a devida vênia, consiste em interpretar o creditamento como um direito inexorável do contribuinte, tendo em vista a previsão constitucional do artigo 153, § 3ำ, inciso II, da Constituição Federal (princípio da não-cumulatividade) e intuito pelo qual as exonerações foram instituídas, em especial, a isenção tributária.

Ora, o fato do contribuinte não ter realizado efetivamente o pagamento do imposto na operação anterior não implica dizer que esse valor não esteja embutido na composição de seu produto final, principalmente por ser o IPI um imposto indireto, o qual, em essência, transmite ao contribuinte de fato a carga tributária correspondente.

Logo, a interpretação literal da expressão "cobrado", presente no citado artigo, 
peca por desconsiderar importantes elementos que culminarão em acúmulo, no produto final, do ônus tributário, como bem salientou o Ministro Ricardo Lewandowski, em voto proferido no Recurso Extraordinário no. 353.657-5/PR.

Interpretação distinta da esposada pelo Ministro Lewandowski, além de ferir o princípio estampado na Magna Carta de não-cumulatividade, esvazia a finalidade conferida às exonerações tributárias - mais especificamente do instituto da isenção, vez que torna mais vantajoso para o industrial adquirir produtos que não tenham recebido qualquer desses benefícios.

Assim, ainda que tenha havido uma mudança no posicionamento do STF, a defesa de tese contrária, propugnada no RE 212.484-2/RS (antigo precedente que confirmou a necessidade do creditamento do IPI em casos de produtos intercorrentes sujeitos à exonerações tributárias), é medida que se faz necessária, porquanto constitui a mais arrazoada e pertinente, por primar pelo respeito e observância dos preceitos maiores ínsitos no texto constitucional.

\section{Referências}

ALVES JÚNIOR, Luís Carlos M artins. 0 creditamento do IPI na aquisição de insumos desonerados. Jus Navigandi, Teresina, ano 12, n. 1876, 20 ago. 2008. Disponível em: বttp://jus2.uol.com.br/doutrina/texto.asp?id=11619>. Acesso em: 03 nov. 2008.

BOTTALLO, Eduardo Domingos. Fundamentos do IPI. São Paulo: Editora Revista dos Tribunais, 2002.

BRASIL. Supremo Tribunal Federal. RE 370.682/RS. Relator M inistro IImar Galvão. Julgamento 25.06.2007. Órgão Julgador: Tribunal Pleno. Publicação: 19.12.2007. Disponível em: বttp://www.stf.jus.br/portal/jurisprudencia/listarjurisprudencia. asp >. Acesso em: 18 nov. 2008.

. Supremo Tribunal Federal. RE 391.822/RS. Relator Ministro Ricardo Lewandowski. Julgamento: 02.09.2008. Órgão Julgador: 1ạ Turma. Publicação: 19.09.2008. Disponível em: বttp:// www.stf.jus.br/portal/jurisprudencia/listarJurisprudencia.asp >. Acesso em: 18 nov. 2008.

. Supremo Tribunal Federal. RE 372.005/ PR. Relator M inistro Eros Grau. Julgamento: 29.04.2008. Órgão Julgador: 2ª Turma. Publicação 16.05.2008. Disponível em: বttp:// www.stf.jus.br/portal/jurisprudencia/listarJurisprudencia.asp >. Acesso em: 18 nov. 2008. 
. Supremo Tribunal Federal. RE 353.657/PR. Relator Ministro M arco Aurélio.

Julgamento: 25.06.2007. Órgão Julgador: Tribunal Pleno. Publicação: 07.03.2008. Disponível em: «ttp://www.stf.jus.br/portal/jurisprudencia/listarjurisprudencia.asp >. Acesso em: 18 nov. 2008.

. Supremo Tribunal Federal. RE 212.484/ RS. Relator Ministro Nelson Jobim. Julgamento: 05.03.1998. Órgão Julgador: Tribunal Pleno. Publicação: 27.11.1998. Disponível em: বhttp://www.stf.jus.br/portal/jurisprudencia/listarjurisprudencia.asp>. Acesso em: 18 nov. 2008.

M ACHADO, Hugo de Brito. Comentários ao código tributário nacional. São Paulo: Atlas, 2003. . Curso de direito tributário. 28 ed. São Paulo: M alheiros Editores, 2007.

M ELO, José Eduardo Soares de. IPI. Curso de direito tributário. Coord. Ives Gandra M artins. 9 ed. São Paulo: Saraiva, 2006. 